III. - ECONOMY

Pig production : short-term prospects

\author{
C. BONSACQUET \\ Ministère de l'Agriculture, Service Central des Etudes et Enquêtes Statistiques \\ 4, avenue de Saint-Mandé, 75570 Paris Cedex 12
}

\begin{abstract}
Short-term pork production forescasting done by S.C.E.E.S. of the Ministry of Agrisulture, applies a simple demographic model linking pig inventories on every April 1, August 1 , December 1 and production in the following twelve months. Forecasting accuracy for the 1975-1981 period is lower than in Germany, but at the same level as in the Netherlands (mean forecasting error : -0.94 p. 100 ; mean absolute forecasting error : 2.51 p. 100). The difficulties arise from the survey data, the model and the definition of the gross indigenous production. The accuracy of the survey data depend on the random error (for a \pm 1 p. 100 accuracy, 40,000 holdings must be surveyed), observation errors, and a possible sample bias (which we try to avoid in updating the list of pig-keeping holdings). Model parameters are also subject to uncertainty. The definition of the gross indigenous production necessitates combining observed data and estimates and counting part of the piglets as slaughter pigs. Recent research should improve the quality of the forecasts : the ADERSA model, research on the GTTT and autoregressive models.
\end{abstract}

\title{
Main elements for pig feed price forecasting
}

\author{
H. MAROUBY \\ I.T.P., Service Economie, 34, bd de la Gare, 31500 Toulouse
}

As pig price forecasting, a management based on forecasting in livestock rearing relies on an estimation of the feed price evolution.

A feed price forecast is carried out three times a year for a 12 -month period and is based on an estimated "feedstuff cost» optimized according to different assumptions as to the main feedstuff used in pig feed.

The main price formation mechanisms on these markets are explained : the relationships between cereal market prices with «official» prices taking into account the growing impact of the world price on the E.E.C. scene, formation of soyabean meal prices within the «oil and protein crop complex $»$ and of other kinds of feedstuff .From 1984, wheat becomes predominant on account of the price fall and soyabean meal slump also contributes to a sharp decrease of pig feed price.

Our study of the 1979-1985 period has helped us to set up indicators which can be used to forecast the range of feedstuff prices. The price formation of other components in the « feedstuff cost» (manioc, bran, other oilmeals) is also explained. The system is illustrated by a recent example : the forecast for feedstuff markets and pig feed prices in 1985-1986. 